\title{
La imaginación, una vía para pensar la educación de las nuevas generaciones*
}

\author{
Nahomi Bonilla Sainz** \\ Recibido: marzo 7 de 2015 • Evaluado: abril 9 de 2015
}

Aceptado: mayo 5 de 2015

\section{Resumen}

Hoy en día visualizar un panorama diferente es de lo que menos se encargan los jóvenes, engullidos en un vertiginoso y voraz mundo, dan por sentado su presente y su futuro, la transformación de dicho panorama empieza hoy, imaginando una realidad diferente, un paisaje más colorido y afable, los docentes podemos ser detonadores para que las nuevas generaciones imaginen horizontes diferentes, permeados de diálogo, respeto, libertad, entendimiento y multiplicidad.

Palabras clave: educación, horizontes, imaginación, dialogo, entendimiento, libertad.

\footnotetext{
" De septiembre de 2011 a febrero a del 2012. Este ensayo surge a partir del profundo acercamiento que tuve con uno de los principales referentes que fundamentaron mi tesis de la Maestría en Investigación de la Danza, Maxine Greene, esta autora es una inspiración para que inicie un sin número de estrategias para transformar no solo mi práctica docente, sino todas las actividades académicas que tengo encomendadas dentro la Facultad de Danza The imagination as a way to think about the education of new generations.

" Doctora en Educación, Directora de la Facultad de Danza de la Universidad Veracruzana, nabonilla@uv.mx e imohanznias@hotmail.com.
} 


\section{Imagination, a way to think about the education of the new generations}

\section{Abstract}

Today display a different picture is the last thing young, swallowed up in a vertiginous and voracious world, they assume their present and future are in charge, the transformation of the picture begins today, imagining a different reality, a landscape more colorful and affable, teachers can be detonators for new generations imagine different horizons, permeated of dialogue, respect, freedom, understanding and multiplicity.

Keywords: education, horizons, imagination, dialogue, understanding, freedom. 


\section{Introducción}

En una ocasión, recuerdo que, durante la clase de filosofía del Doctorado en Educación, mientras hablábamos de Nietzsche, el maestro decía -la cuestión es que debemos de vivir una vida que merezca ser vivida- y desde ese momento me he preguntado ¿Qué o cómo es una vida que merezca ser vivida? ¿Qué puedo hacer para que esta vida sea una vida que merezca ser vivida? ¿Esta vida que tengo es una vida que merezca ser vivida?

Ahora traigo a mi mente estos cuestionamientos porque al leer el libro Liberar la imaginación de Maxine Greene (2005), me parece que existe esa posibilidad de vivir una vida que merezca ser vivida, pero no solo para mí, sino que también existe la posibilidad de gestionar que mis estudiantes puedan generar sus propias versiones de una vida que merezca ser vivida.

Si bien el panorama político, social, económico y cultural que podemos advertir, no es nada alentador, existen dos posibilidades entre las que podemos elegir, una, la de dejarnos llevar por visiones derrotistas, mediocres y pesimistas, o perspectivas de vida que responden a los intereses de la clase dominantes, en las que la cultura del consumo, el individualismo, la comercialización, lo superfluo es lo relevante y, la otra, la de resistirse " a ser llevado por la corriente", la de tener esperanza, la que se origina a partir de imaginar horizontes diferentes.

[...] estoy convencida de que, en los actuales ambientes educativos, las personas tienen la opción de resistirse a la irreflexión, la banalidad, la racionalidad técnica, la desatención y las «salvajes desigualdades» (Közol, 1991) que continuamente erosionan la educación pública. (Greene, 2005, p. 11)

Greene (2005) propone que mediante la imaginación podemos organizar un mundo coherente y generar empatía entre los seres humanos, esto es, la imaginación nos permite descubrir realidades diferentes, que, aunque no las lleguemos a aprobar o a entender del todo, sí podemos entender nuestra realidad personal tanto como para concebir la existencia de otras posibles realidades.

Para Greene (2005) los encuentros con el arte son un medio para construir perspectivas diferentes del mundo, es decir, estos encuentros pueden provocar salirse de lo habitual, de lo común y corriente e imaginar lo particular, lo extraordinario. 
$\mathrm{Al}$ igual que existen formas de provocar la imaginación de cada individuo, también es posible provocar una imaginación colectiva, o imaginación social como la llama Greene (2005), la cual define como: "la capacidad de inventar visiones de cómo debería y podría ser nuestra deficiente sociedad, de cómo deberían y podrían ser las calles en las que vivimos o nuestras escuelas" (p. 17).

Como maestra busco promover la imaginación social en mi entono escolar, pretendo hacer de mi salón de clase un lugar en donde podamos imaginar diferentes horizontes, encontrar múltiples respuestas, facilitar el diálogo e ir construyendo realidades de acuerdo a nuestras necesidades, inquietudes, expectativas, gustos, aptitudes, anhelos, sueños, fantasías, etc., y entonces, es posible que a través del recorrido por la multiplicidad de horizontes, logremos imaginar posibilidades comunes, y con ello, crear espacios en los que la libertad de pensamiento no sea obstáculo para los acuerdos, en donde, las diferencias sean una fuente de inspiración para pensar realidades diferentes a las que vivimos, a las que nos han sido impuestas, a las preestablecidas. Al respecto Greene (2005) menciona: "Deseo ayudar a que pensemos más allá de la escolarización y nos fijemos en los terrenos más amplios de la educación en general, donde hay y debe haber toda clase de oportunidades y posibilidades" (p. 18).

Imaginar una comunidad libre, democrática, más humana, más empática implicaría, que nosotros los educadores, impulsáramos la participación de los jóvenes en nuestra comunidad. Greene (2005) considera que recuperar la imaginación puede aminorar la parálisis social en la que vivimos y con ello podríamos tener la sensación de que estamos haciendo algo en nombre de la dignidad humana.

Es también necesario que los educadores agudicemos la conciencia de nuestros alumnos para que ellos puedan encontrar significados, respuestas, posibilidades.

Si somos conscientes, los significados surgen a nuestro alrededor, por todas partes, y, por tanto, los profesores tienen el deber de hacer más aguda la conciencia de todo aquél a quien enseñan instándolo a leer y a mirar y a extraer sus propias interpretaciones de lo que ve. (Greene, 2005, p. 62)

Los educadores que imaginan posibilidades distintas para sus alumnos necesitan mostrarles que valen, que tienen el poder de decidir y actuar, que 
pueden hablar desde su perspectiva del mundo, y que con ello conseguirán la posibilidad de edificar un mundo coherente consigo mismos, pero además al expresarse en espacios compartidos se pueden encontrar confluencia con otros y generar ideas, iniciativas, intereses y creencias compartidas.

Pero desde el momento en que se presta atención a la diferenciación de las múltiples voces presentes en un aula, aumenta la importancia de que se reconozcan creencias compartidas. Tales creencias solo pueden surgir del diálogo y el respeto hacia los demás y hacia su libertad y su posibilidad. (Greene, 2005, p. 72)

Sin embargo, no es suficiente que los profesores y alumnos manifiesten sus puntos de vista y convengan nuevas posibilidades, sino que también, es necesario que se proyecten hacia otras posibilidades, ello deriva en una constante oportunidad para el cambio y replanteamiento de ideas, antídoto para el anestesiamiento del que tanto nos vemos invadidos.

Aunque como profesores no podemos, ni determinar el mundo común por construirse, ni justificar anticipadamente el tipo de comunidad que se está creando, sí podemos propiciar ambientes de diálogo, confianza, reflexión e imaginación, ambientes de aprendizaje en los que prevalezcan principios y valores como la justicia, la libertad, el respeto, la dignidad, la empatía, el amor.

Nuestras aulas deberían ser educativas y reflexivas al mismo tiempo: deberían latir con múltiples concepciones de lo que es ser humanos y estar vivos. Deberían resonar en ellas las voces de personas jóvenes, capaces de expresarse, que participan en diálogos siempre incompletos. Debemos aspirar a que nuestros estudiantes logren la amistad al tiempo que en cada uno de ellos se avivan la conciencia, la acción imaginativa y una renovada sensación de posibilidad. (Greene, 2005, p. 73)

Descubrir, a través de la imaginación, los caminos para pensar nuevas alternativas de vida son determinantes para no caer en el torbellino vertiginoso del "falso progreso" del "prometedor futuro", me pregunto, ¿progreso, para quién?, ¿progreso en qué sentido?, ¿cuáles son los parámetros que determinan tal progreso? considero que no existe un futuro prometedor si no existe hoy un presente alentador. 
Justamente Greene (2005) imagina una pedagogía que debería, de algún modo, reparar los embates del mundo moderno, un mundo que ha sido definido por un riguroso positivismo, por un despiadado capitalismo, un mundo que ha desarrollado un lenguaje que responde a los intereses de un pequeño pero poderoso grupo de la sociedad, es un mundo en que lo que menos interesa es exhortar a sus generaciones jóvenes a descubrir y buscar los paisajes de su vida, a significar sus experiencias vividas, a "apropiarse de visiones y perspectivas legítimamente suyas" (p. 81).

En relación a la pedagogía que Greene (2005) concibe, ella sugiere, a quienes enseñamos, que:

1. Nuestros esfuerzos para entender a los jóvenes y recuperar nuestros propios paisajes deben ir unidos a nociones de praxis pedagógica.

2. Las pedagogías que diseñemos deberían provocar un acentuado sentido de agencia en aquellos y aquellas a quienes enseñamos.

3. Nos deberían habilitar para perseguir nuestra propia libertad y, quizás, para transformar, hasta cierto punto, nuestros mundos vividos.

Y aunque no hay mapas específicos que nos guíen para construir una mejor sociedad, mucho menos para construir un mejor sistema escolar, sí estaría bien que empezáramos a concebir procesos diferentes, a imaginar paisajes, paisajes propios en los que podamos visualizar tal cual lo que queremos.

Crear una Pedagogía como la que Greene (2005) expone no es fácil, por lo que los que enseñamos debemos estar conscientes de que:

1. Las personas que enseñamos compartimos una conciencia cultural, característica de los intelectuales occidentales, y esto nos hace «agentes de ese sistema de poder» (Foucault, citado en Greene, p. 84).

2. Hay estructuras sociales que se interponen obstaculizando el libre juego de energías, el despertar de la conciencia, la autenticidad y la sensibilidad moral.

3. La última advertencia tiene que ver con la condición humana misma, con las experiencias de lo absurdo por las que pasamos cuando nuestras preguntas existenciales más profundas se encuentran con el silencio de perplejidad como respuesta.

De ahí que, una pedagogía liberadora y transformadora como la que Greene plantea, comprendería las siguientes particularidades: 
- Una característica de la pedagogía transformadora que Greene (2005) expone es que deben relacionarse las condiciones existentes con lo que se está tratando de generar.

- “Como también dijo Sartre, ese ir más allá es lo que caracteriza en esencia a una persona; eso y lo que esa persona logra hacer a partir de aquello en lo que la han convertido" (Sartre citado en Greene, 2005, p. 87).

- Esta pedagogía debería de tener el interés de crear una civilización que pueda tolerar la potencia del deseo, el empuje de las energías diversas, la vitalidad del juego y la intención de transformar.

- La pedagogía liberadora solo puede liberar aquello que se percibe como represión, es decir, "solo buscamos esa libertad cuando lo que reprime (o lo que condiciona o limita) se percibe como un obstáculo" (Greene, 2005, p. 87).

- Una de las preocupaciones cruciales de toda pedagogía humana y crítica es "hacer posible que los niños tengan un mundo significado y significante" (Greene, 2005, p. 91), es decir, que los niños, quienes viven en un mundo de horizontes en constante cambio, puedan imaginar lo que está por venir, y adquieran conciencia del descubrimiento, y la consolidación de los significados que van acumulando; descubran algo acerca de cómo leer el mundo.

- Los profesores debemos hacer un esfuerzo para romper con la costumbre y promover la conciencia de los jóvenes a quienes enseñamos.

- "Sin duda, la educación debe ser concebida hoy en día como un modo de abrir el mundo a los juicios críticos de los jóvenes y a sus proyecciones imaginativas y, llegado el momento, a sus acciones transformadoras” (Greene, 2005, p. 92).

- A pesar de que conocemos y reconocemos el proceso de reproducción cultural que se da en nuestra sociedad, y por supuesto en nuestras escuelas, es posible que como maestros, insistamos en la reapropiación de las formas culturales por parte de nuestros alumnos, mediante el énfasis de enfoques interpretativos y críticos, de romper con los márgenes prestablecidos, y dar paso a las nuevas e inesperadas formas de lectura, y además si comprendemos que los jóvenes indagan, traspasan los límites convencionales, buscan coherencia y explicaciones, estaremos 
en una mejor disposición para provocar y liberar, en vez de imponer y controlar.

- En la medida en que los jóvenes tienen la capacidad de concebir múltiples realidades empiezan a nombrar sus mundos, esto es un factor que se da a partir de la familiaridad de las redes conceptuales y de los sistemas de símbolos característicos de la forma que tiene la cultura de dar sentido a las cosas. "Los jóvenes pueden ser habilitados para verse a sí mismos como unos "nombradores» y unos hablantes conscientes y reflexivos si se reconocen sus puntos de vista particulares, si se potencian los diálogos interpretativos, si se mantiene viva la interrogación" (Greene, 2005, p. 96).

- Greene (2005) propone que, como parte de esta pedagogía, se capacite a los alumnos para que manejen una serie de lenguajes que no sean exclusivamente los verbales o los matemáticos, sino también los lenguajes artísticos.

- Para que esta pedagogía prospere, el desarrollo de las capacidades imaginativas debe de ser de ambas partes, es decir, no solo los alumnos deben revelar sus mundos vividos, sino que también los maestros deben de revelar los suyos, esto depende de que se propicien ambientes de diálogo, de apertura, de reflexión, en donde tanto los alumnos como los maestros se expresen con sus propias voces y construyan un espacio intermedio.

Aunque lo que Maxine Greene propone nos parezca un tanto utópico, no cabe duda, de que lo que nos ofrece es la posibilidad de crear realidades diferentes, realidades que, por medio de la imaginación, podemos ir confeccionándo de acuerdo a las características intrínsecas de cada quien. Con una imaginación que responde a la voz de cada uno de nosotros, no puede originarse otra cosa, que no sean los paisajes que cada uno visualizamos para nuestra vida. 


\section{Referencias}

Eisner, E. W. (2005). Educar la visión artística. Barcelona: Paidós

Ferreiro, A. (2007). Una topografía de la imaginación. Rutas para pensar la educación. En Jiménez García, M. A. (coor.). Encrucijadas de lo imaginario. Autonomía y práctica de la educación. México: UACM/Seminario Interinstitucional Cultura, Educación e Imaginario Social.

Greene, M. (2004). Definir la educación estética y Notas sobre educación estética. En Variaciones sobre una guitarra azul. Conferencias de educación estética. (pp. 15-55). México: Edere.

Greene, M. (2005). Liberar la imaginación. Ensayos sobre educación, arte y cambio social. Barcelona: Graó. 